\title{
Evaluation of postural control in children and adolescents with down syndrome aged eight to twelve years old
}

Oopen acess

${ }^{1}$ Londrina State University, Londrina - Brazil.

Corresponding author:

jessicacristina_leite@yahoo.com

Manuscript received: October 2017 Manuscript accepted: December 2017

Version of record online: March 2018
Jessica Cristina Leite', Jessica Caroliny de Jesus Neves ${ }^{1}$, Leonardo George Victorio Vitor ${ }^{1}$, Dirce Shizuko Fujisawa ${ }^{1}$

\section{Abstract}

Introduction: Down Syndrome is a genetic disorder caused by the presence of the third copy of chromosome 21 (total or partial). The syndrome occurs in approximately one out of every $700-1000$ newborns per year.

Objective:To analyze postural control (PC) of children and adolescents with Down Syndrome (DS) and to compare differences regarding age, sex, nutritional status, and physical activity (PA) levels.

Methods: In this cross-sectional study, a convenience sample composed of 21 children and adolescents ( 9 girls) was categorized according to age: $\mathrm{G} 1$ (8 to 9 years old; $\mathrm{n}$ = 8), G2 (10 years old; $n=7$ ), and G3 (11 to 12 years old; $n=6)$, Score-Z: eutrophic $(n=9)$ and overweight $(n=12)$, and PA level: practitioners $(n=7)$ and non-practitioners ( $n$ $=14$ ). $P C$ was assessed in the force platform (FP), in the standing position, with feet together during 30 seconds. The variables analyzed were the center of pressure area (COP) and the mean velocities of anteroposterior and mediolateral oscillation (VEL-AP and VEL-ML). Shapiro-Wilk test was used to test the normality of data. Kruskal-Wallis, Dunn's, and Mann Whitney tests were performed to analyze associations with PC. Statistical significance was set at $p<0.05$.

Results: The median COP, VEL-AP and VEL-ML were 3.55 [2.13 - 6.82] , 2.81 [2.32 - 3.16], and 2.98 [2.42 - 3.43], respectively. There were no differences in $\mathrm{PC}$ regarding sex, body mass index and PA level. The adolescents in G3 presented lower values of VEL-AP (G1=2,88 [2,82 - 3,21]; $\mathrm{G} 2=2,94[2,35-3,39] ; \mathrm{G} 3=2,27[2-2,3])$ and VEL-ML $(\mathrm{G} 1=$ 3,22 [3,14-3,68]; G2= 2,91 [2,52 - 3,63]; G3=2,34 [2,1 $2,39])$.

Conclusion: Sex, nutritional status, and PA level did not affect COP area and AP-VEL and ML-VEL. However, strategies were affected by age, as observed by differences in velocity, but did not affect the COP area.

Keywords: down syndrome, postural balance, motor activity, anthropometry. 


\section{INTRODUCTION}

Down Syndrome (DS) is a genetic disorder caused by the presence of the third copy of chromosome 21 (total or partial). The syndrome occurs in approximately one out of every $700-1000$ newborns per year ${ }^{1,2}$. The life expectancy is increasing and currently is around 55 -60 years old ${ }^{1,3}$. The syndrome is frequently associated with morbidities or adverse clinical conditions ${ }^{3,4}$. The development of neuromotor control and mental skills allow children with DS to partake social life, which is considered one of the primary purposes of rehabilitation because of its direct impact on quality of life and life expectancy ${ }^{5}$.

The sensorial integration disorders present in children with DS lead to a late development of postural control (PC) that can last until adulthood'. The PC in DS is also affected by inadequate muscle co-contraction, limited repertory of movements, myo-osteo-articular and

\section{METHODS}

In this cross-sectional study, a convenience sample was composed of 21 children and adolescents ( 9 girls/12 boys) diagnosed with DS (confirmed by karyotype), aged 8 - 12 years old were included. Data were collected between May 2016 and October 2016. Participants were excluded if they could not sustain the orthostatic position; had orthopedic alterations; presented any chronic diseases and/or sensorial deficits different than those typically observed in DS; presence of comorbidities or any condition that precluded the conduction of assessments, including lack of comprehension/collaboration. All participants were recruited from the "Associação de Pais e Amigos de Portadores de Síndrome de Down (APS Down)" and from the "Instituto Londrinense de Educação para Crianças Excepcionais (ILECE)", both institution located in the city of Londrina, Paraná, Brazil.

This study was approved by the Institutional Review Board (number 1.336.881/2015), the participants were informed about the procedures and signed a consent form (document signed by the parent or guardian). Personal information and medical history (surgeries, comorbidities, and medication) were reported by the guardian of the participant.

\section{Anthropometric data}

Body weight and height were measured using a scale (Welmy, model 110, n. 6308, Brazil). The nutritional status was performed in specific software (Anthro WHO Plus, WHO), using body weight, height, and body mass index. Children and adolescents with z score values lower than -2 were classified as "low body weight", values between -2 and +1 as "eutrophic", values between +1 and +2 as "overweight", and values higher than +2 as "obese" 12 . The comparison of PC according to the nutritional status was performed using two groups: "eutrophics" and "over normal weight". The latter included overweight and obese participants.

\section{Physical Activity}

Habitual physical activity (PA) was reported (type central nervous alterations ${ }^{7,8}$. Adequate control of body balance is a requirement to perform activities of daily living, preventing the risk of falls in children and avoiding limitations of functional performance ${ }^{\text {. }}$

It is well established that adequate PC in children with normal development depends on factors such as age, anthropometry, biomechanical aspects and physical conditioning ${ }^{10,11}$. In children with DS, there is limited information about PC and its influencing factors. Such information is important to the conception of rehabilitation programs aiming to improve daily life participation. Despite the importance of the assessment of PC in DS, it remains underused in the clinical routine. Therefore, the aim of the present study was to analyze the PC of children and adolescents with DS and to compare differences regarding age, sex, body mass index, and physical activity (PA) level.

and frequency). They also answered the translated and validated version of the Physical Activity Questionnaire for Children (PAQ-C). In this version of the questionnaire (Silva and Malina, 200), activities not relevant to Brazilian children are excluded ${ }^{13}$. PAQ-C assesses the amount of PA in children and adolescents during the previous seven days ${ }^{14}$. A final score is calculated and participants were classified as "active" if total score $\geq 3$ or "sedentary" if total score $<3^{15}$. The comparison of PC according to the participation in regular PA was performed comparing practitioners and non-practitioners.

\section{Postural control}

PC was assessed using a gold standard force platform (FP) (Biomec 411, EMG System, Brazil) ${ }^{16}$. The platform is composed of two rigid surfaces (one superior and one inferior) connected by four strain gauges that measure the vertical component of force to the ground. Using specific software (EMG System, Brazil), forces were used to calculate the center of pressure (COP) and variables related to the space-time variation. The FP transforms body oscillations (changes of the center of mass) into electrical signals that are amplified and stored for analysis. Measurements of anteroposterior and mediolateral oscillations were derived from the signals of the analysis ${ }^{17}$. FP was calibrated, and the parameters used were the area of COP (A-COP) in $\mathrm{cm}^{2}$, mean velocity of oscillations in $\mathrm{cm} / \mathrm{s}$ of anteroposterior (VEL-AP) and mediolateral (VEL-ML). The outcomes chosen are the most reliable and sensitive to detect differences in PC in various populations ${ }^{18}$.

The protocol used to analyze balance at the FP followed a standardized setting: All participants performed three attempts at a specific posture for 30 seconds. Resting time between each attempt was set as one minute, and the average used in the analysis ${ }^{19}$. Using a pilot study, we decided to use a position that participants were standing with feet together and eyes open. This position was the most challenging posture that could be sustained for the given time of 30 seconds. Children and adolescents 
were instructed to remain quiet and concentrated with the upper limbs alongside the body while staring at a fixed point at the height of their eyes. All the assessments were performed by two experienced investigators.

Data from FP was collected using a sample rate of $100 \mathrm{~Hz}$ and analyzed in a computer using specific software (Bioanalysis, EMG system, Brazil). All signals were filtered using a second-degree function (Butter worth filter), and a frequency band of $0-35 \mathrm{~Hz}$ to eliminate electrical noise. Data acquisition and treatment was performed using computational routines of stabilographic analysis in MATLAB (The Mathworks, USA).

\section{Data analysis}

The comparison of PC according to the age was performed stratifying participants into three groups (G1, G2 and G3): G1 ( $8-9$ years old; $n=8)$; G2 (10 years old;

\section{RESULTS}

21 participants with DS were assessed, 12 boys $(57 \%)$ and nine girls $(43 \%)$, with median age of 10 [8 11] years old, 35 [29,5 - 43,5] $\mathrm{Kg}$ of body weight and $129[122,5-136,5] \mathrm{cm}$ of height. One participant $(5 \%)$ had corrected congenital heart disease, three (14\%) had hypothyroidism, and two $(9,5 \%)$ used continuous medication for hyperactivity.

The results of PAQ-C classified 20 (95\%) of the participants as sedentary and one $(5 \%)$ as active. The median score in the questionnaire was 2,29 [1,87-2,6]. Seven $(33 \%)$ participants reported being engaged in regular PA. Six participants had swimming classes, and one was engaged in a PA program including various activities, performed twice a week.

The median values of COP, VEL-AP, and VEL-ML were 3.55 [2.13-6.82], 2.81 [2.32 - 3.16], and 2.98 [2.42 $-3.43]$, respectively. No differences were found between the three groups according to age for $\mathrm{COP}(\mathrm{G} 1=4.86$ $[3.33-6.63] ; \mathrm{G} 2=2.13[1.89-7.51]$, and G3=3.50 [2.42 - 4.85]). However, adolescents in G3 had significantly lower VEL-AP $(\mathrm{G} 1=2.88$ [2.82 - 3.21]; G2= 2.94 [2.35 $-3.39] ; \mathrm{G} 3=2.27[2.0-2.3])$, and VEL-ML $(\mathrm{G} 1=3.22$ $[3.14-3.68] ; \mathrm{G} 2=2.91[2.52-3.63] ; \mathrm{G} 3=2.34[2.10$ - 2.39]) than G1 and G2 (Figure 1, Figure 2, Figure3).

\section{COP}

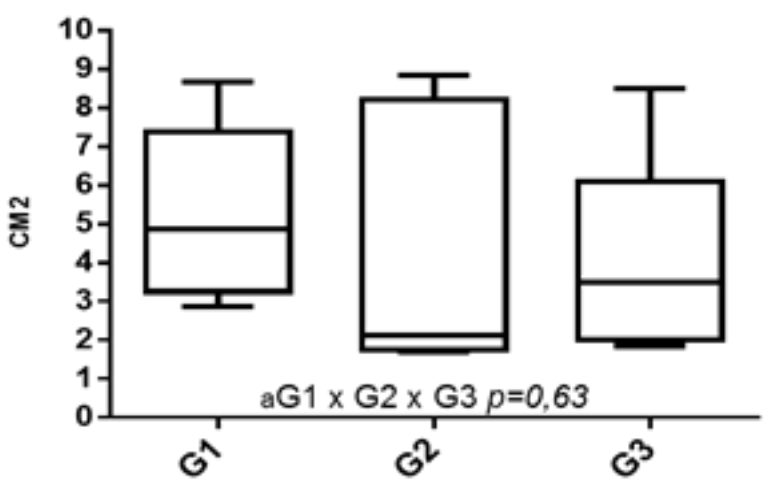

Figure 1: Center of pressure area according to age.

a; Intergroup analysis $\mathrm{n}=7)$, and G3 (11 - 12 years old; $\mathrm{n}=6)$. The comparison of $\mathrm{PC}$ according to nutritional status was performed using two groups (G1 and G2): G1 (eutrophics; n=9) and G2 (over normal weight; $\mathrm{n}=12$ ). PC was also compared according to sex: 12 boys (57\%) and nine girls (43\%); and according to PA level: seven practitioners (33\%) and 14 (67\%) non-practitioners.

Data were inserted in an electronic spreadsheet (Excel, Microsoft Inc., USA), and the statistical analysis was performed using the software Prism (GraphPad, USA). Data distribution was checked using the ShapiroWilk test. Comparison of PC according to age was performed using the Kruskal-Wallis test with Dunn's posthoc. Comparisons of PC between sex, nutritional status, and PA level were performed using the Mann-Whitney test. Statistical significance was set at $\mathrm{p}<0.05$.

No differences were found in PC between sex (COP $p=$ 0.79; VEL-AP $p=0.96$; and VEL-ML $p=0.85)$, nutritional status (COP $p=0.30$; VEL-AP $p=0.15$; and VEL-ML $p=$ $0.15)$ and PA level (COP $p=0.13$; VEL-AP $p=0.71$; and VEL-ML $\mathrm{p}=0.22$ ) (Table 1).

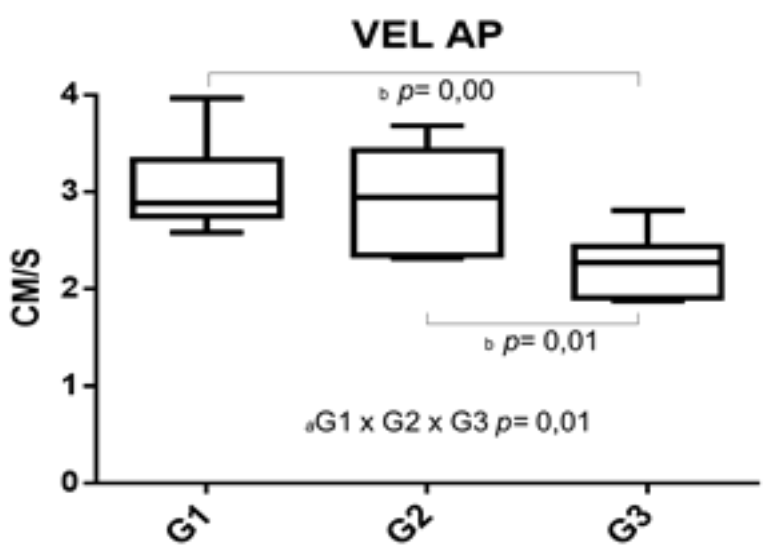

Figure 2: Anteroposterior velocity according to age. a; Intergroup analysis b; Intragroup analysis

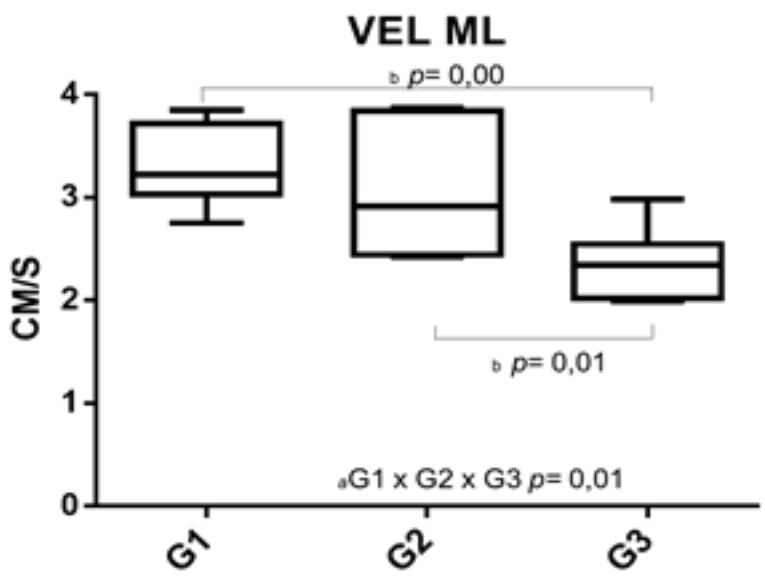

Figure 3: Mediolateral velocity according to age. a; Intergroup analysis, b; Intragroup analysis 
Table 1: Postural control regarding sex, z score and physical activities.

\begin{tabular}{lccc}
\hline & COP & VEL-AP & VEL-ML \\
\hline SEX & & & \\
Boys & $3.50[1.88-5.93]$ & $2.78[2.31-3.33]$ & $3.08[2.40-3.61]$ \\
Girls & $4.19[1.86-7.89]$ & $2.74[2.39-3.16]$ & $2.91[2.45-3.48]$ \\
P value & 0.79 & 0.96 & 0.85 \\
Z SCORE & & & \\
Eutrophic & $3.37[2.13-4.97]$ & $2.87[2.36-3.43]$ & $3.25[2.60-3.67]$ \\
Over normal weight & $5.00[2.93-7.24]$ & $2.64[2.30-2.90]$ & $2.83[2.36-3.03]$ \\
P value & 0.30 & 0.15 & 0.15 \\
Physical Activity & & & \\
Yes & $7.00[4.25-8.13]$ & $2.58[2.32-2.91]$ & $2.75[2.38-2.94]$ \\
No & $3.41[2.10-4.91]$ & $2.83[2.33-3.31]$ & $3.19[2.46-3.61]$ \\
P Value & 0.13 & 0.71 & 0.22 \\
\hline
\end{tabular}

$\mathrm{COP}=$ center of pressure area; VEL-AP= mean velocity of anteroposterior oscillation; VEL-ML= mean velocity of mediolateral oscillation.

\section{DISCUSSION}

The present study demonstrated a high prevalence of overweight and obesity in the investigated participants (43\% and $14 \%$, respectively), corroborating with previous finding $\mathrm{s}^{20,21}$. Abnormally high weight at childhood may induce short and long term physical consequences, such as hypertension, hypercholesterolemia, diabetes, cardiovascular diseases, chronic pain, increased risk of falls, depression, social isolation, persistency of overweight during the adult life and reduction in life expectancy ${ }^{22,23}$. Lobestein et al..$^{24}$ estimated a significant increase in worldwide levels of comorbidities and overweight in children by 2025 . It was also estimated that 11.4 million children would be overweight in Brazil $^{24}$. Bertapelli et al. ${ }^{25}$ reported that young people with DS are more likely to be overweight than the general population, and the prevalence of overweight and obesity vary between $23 \%$ and $70 \%{ }^{25}$. Studies also point out to possible factors determining these nutritional alterations, including reductions in basal metabolism, comorbidities, poor dietary habits and low levels of $\mathrm{PA}^{13,26}$.

Children and adolescents with DS present health, anatomical, physiological, cognitive, and psychosocial factors that limit the practice of $\mathrm{PA}^{27}$. Patients also need to cope with bigger problems, such as difficulty in transportation, lack of motivation, and insufficient integrative programs ${ }^{28}$. Such aspects may at least in part explain the low levels of PA in our sample, as $95 \%$ of participants were classified as sedentary. The scientific literature recommends 60 minutes of daily moderate PA for children and adolescents. Although young people with DS do not reach this recommendation, there is no specific guideline that considers the features of the disease, such as worsened cardiovascular condition, muscle force/ endurance, and poor bone density ${ }^{29,30}$.

In the present study, the regular PA of the seven participants was not enough to alter PAQ-C classification from sedentary to active, which is likely due to the amount of sedentary behavior and activities of low intensity in the remaining periods of the day. Even toying activities can be different in children with DS as it will involve activities with a lower neuromotor challenge, like running and jumping ${ }^{31}$. Therefore, therapists should act as facilitators, providing with playful opportunities to children with DS.

Amongst the activities recommended for infants, swimming and water exercises stand out from regular activities because of its dynamic characteristic, increased energy expenditure, high adherence capacity, cardiorespiratory conditioning, pleasantness, and by involving diverse muscle groups ${ }^{32}$. The American College of Sports Medicine suggests that obese people practice low weight bearing activities ${ }^{33}$. Swimming is a sport that reduces articular overload and, therefore, reduces injuries related to the exercise. Thus, such benefits would be important for the investigated population. Amongst the seven participants $(33 \%)$ attending regular PA, six were engaged in swimming classes twice a week. This finding should be seen as an encouragement to the remaining sample.

Baccouch et al. ${ }^{34}$ reported better PC at the bipedal position with closed eyes in adolescents following swimming classes in comparison to a control group ${ }^{34}$. In the present study, there was no significant difference in PC between participants engaged or not into regular PA, likely due to the influence of other aspects observed in children and adolescents with DS that interfere more with its performance.

The COP medians in G1 and G2 according to age were 4.86 [3.33 - 6.63], and 2.13 [1.89 - 7.51], respectively. These values were similar to the reported by Lemos et al. ${ }^{35}$, that found $4.39 \pm 0.85$ for children with ordinary development at the age of eight $(4.12 \pm 1.91)$, nine $(2.94 \pm 1.04)$, and ten years old. On the other hand, the values of VEL-AP (G1=2.88 [2.82 - 3.21]; G2=2.94 [2.35 - 3.39]), and VEL-ML $(\mathrm{G} 1=3.22$ [3.14 - 3.68]; $\mathrm{G} 2=2.91[2.52-3.63])$ were larger than those reported by Lemos et al., who reported total VEL of $1.31 \pm 0.25$; $1.18 \pm 0.32$ and $1.08 \pm 0.22$ for eight, nine and ten years old, respectively. 
In the present study, children and adolescents with DS reached similar values of COP without any significant difference despite the lower velocities in the group of older participants (G3). Such results demonstrate that the PC, based on the COP area, is similar between children with or without DS between eight and ten years old. However, the strategy adopted vary as observed by the higher oscillation velocities in younger children with DS. This response can be explained by the musculoskeletal alterations in DS, as muscle hypotonia and ligament laxity are common characteristics observed in children with DS. These characteristics induce a worsened adaptation of its motor actions to different circumstances and generate more force whenever necessary. Furthermore, these are characteristics that affect the general mobility and increase the difficulty to perform synchronized movements as to maintain balance? .

These results, however, were not observed when comparing G1 and G2. This finding can be explained by the influence of inherent factors to the syndrome itself. For instance, in the group of children of ten years old, one participant with COP of $1.76 \mathrm{~cm}^{2}$ presented values of VEL-AP and VEL-ML of 3.68 and $3.84 \mathrm{~cm} / \mathrm{s}$, respectively. In the same group, one participant with COP of $8.85 \mathrm{~cm}^{2}$ (higher value) obtained similar values of velocity (3.36 and $3.87 \mathrm{~cm} / \mathrm{s}$ ), confirming the large variability.

Sousa et $a l .{ }^{36}$ compared PC of 43 children with hearing disorder with 57 children with normal development aged between 7 and ten years old. The study did not find differences in the mean of COP and total VEL at the positions of feet together and separated with open eyes. Children with hearing disorder presented higher anteroposterior values $(-6.77 \pm 2.76$ versus $-5.74 \pm 2.12$; $\mathrm{p}=0.04$ ) only during the bipedal position with closed eyes. Similar to the participants with DS in our study, the difference in the postural control between children with and without hearing disorder may be a consequence of the impaired sensorial integrative in both populations ${ }^{7}$.

Few studies propose that children reach PC level similar to adults at seven and eight years old ${ }^{10}$. Hsu et al. ${ }^{37}$ assessed this relationship in 251 children aged three to twelve years old and concluded that the transition of PC to one that is equal to adults ends by the age of twelve. Rigoldi et $a l .{ }^{6}$ also investigated the influence of age on PC in children, adolescents, and adults with DS and found differences according to age and between subjects with or without DS. The results were also observed in adults, likely due to the development of compensatory strategies to counteract alterations, such as muscle hypotonia and

\section{CONCLUSION}

The present study verified that PC in children and adolescents with DS are different than in children with typical development, regarding the oscillation velocity described in the literature.

Sex, nutritional status, and PA level did not affect COP area, AP-VEL, and ML-VEL. However, strategies were affected by age, as observed by differences in velocity, but did not affect the COP area. The PC of children and adolescents with DS ligament laxity. These results corroborate the present findings, which showed differences in PC according to VEL-AP and VEL-ML in participants of different ages.

Due to the hyperactivity of boys, girls with ordinary development present better $\mathrm{PC}^{38}$. Studies also point out for differences in PC between eutrophic and obese children ${ }^{11}$. However, such differences (sex and nutritional status) were not observed in the present study. Sousa et al. ${ }^{36}$ also failed to find differences in PC between sex in children with hearing disorders. The authors justified the lack of differences based on the fact that preschoolers' body structure is similar regardless sex, being almost impossible to distinguish when seen from the posterior view.

In the present study, the $\mathrm{z}$ score proposed by the WHO was used to classify the nutritional status in children and adolescents. Recently, specific growth curves for children and adolescents with DS were proposed by the Center for Disease Control and Prevention (CDC) $)^{39}$. Although the proposed curves identify the specific growth pattern observed in this population, its application is limited by a series of factors, such as low capacity to generalize (sample composed of only American children). A Brazilian study also proposed growth curves for children with DS. However, it only classifies children up to eight years old ${ }^{39,40}$.

The results emphasize the need for awareness and action of parents and health/education professionals regarding lifestyle changes among children and adolescents with DS as a strategy to reduce the prevalence of obesity and sedentary behavior. Also, integrated health programs for children and adolescents with DS should consider PC as an important factor to be developed, given the differences observed in children with normal development. Sensory integration is an approach that can benefit children and adolescents with SD by prioritizing the use of sensory systems that combines vestibular, proprioceptive and tactile experiences during the performance of functional activities $^{41}$.

The reduced sample size is a limitation of the present study. However, it is important to highlight the difficulty in recruiting participants with DS and that all children and adolescents who met the criteria were included. Furthermore, the use of PAQ-C to classify PA is also a limitation as questionnaires are considered subjective instruments. It is suggested that new studies include interventions and long-term follow-up to better investigate the influence of PC on other possible influencing factors.

is mainly determined by the characteristics of the syndrome, and it is influenced by age, since there might be a relationship with the maturation of the systems, essentially coming from experiences in childhood. 


\section{REFERENCES}

1. Castro-Piñero J, Carbonell-Baeza A, Martinez-Gomez D, Gómez-Martínez S, Cabanas-Sánchez V, Santiago C, et al. Follow-up in healthy schoolchildren and in adolescents with Down syndrome: psychoenvironmental and genetic determinants of physical activity and its impact on fitness, cardiovascular diseases, inflammatory biomarkers and mental health; the UP\&DOWN Study. BMC Public Health. 2014;14:400. DOI: https://doi.org/10.1186/1471-2458-14-400

2. Coppedê F. Risk factors for Down syndrome. Arch Toxicol. 2016;90(12):2917-29. https://doi.org/10.1007/s00204-016-1843-3

3. Sobey CG, Judkins CP, Sundararajan V, Phan TG, Drummond GR, Srikanth VK. Risk of Major Cardiovascular Events in People with Down Syndrome. Plos One. 2015;10(9):e0137093. DOI: https://doi.org/10.1371/journal.pone.0137093

4. Bull MJ, Committee on Genetics. Health supervision for children with Down Syndrome. Pediatrics. 2011;128(2):393-406.

5. Matute-Llorente A, González-Aguero A, Gómez-Cabello A, Vicente-Rodríguez G, Casajús JA. Decreased levels of physical activity in adolescents with down syndrome are related with low bone mineral density: a cross-sectional study. BMC Endocr Dis. 2013;13:22. DOI: https://doi.org/10.1186/1472-6823-13-22

6. Rigoldi C, Galli M, Mainard L, Crivellini M, Albertini G. Postural control in children, teenagers and adults with Down syndrome. Res Dev Disabil. 2011;32(1):170-5. DOI: https://doi.org/10.1016/j.ridd.2010.09.007

7. Malak R, Kotwicka M, Krawczyk-Waslelewska A, Mojs E, Samborski W. Motor skills, cognitive development and balance functions of children with Down syndrome. Ann Agric Environ Med. 2013;20(4):803-6.

8. Karmiloff-Smith A, Al-Janabi T, D'Souza H, Groet J, Massand E, Mok K, et al. The importance of understanding individual differences in Down syndrome. F1000 Res. 2016;5:F1000. DOI: http://dx.doi.org/10.12688/f1000research.7506.1

9. Cabeza-Ruiz R, García-Massó X, Centeno-Prada RA, Beas-Jiménez JD, Colado JC, González LM. Time and frequency analysis of the static balance in young adults with Down syndrome. Gait Posture. 2011;33(1):23-8. DOI: http://dx.doi.org/10.1016/j.gaitpost.2010.09.014

10. Verbeque E, Vereeck L, Hallemans A. Postural sway in children: a literature review. Gait Posture. 2016;49:402-10. DOI: http://dx.doi.org/10.1016/j.gaitpost.2016.08.003

11. Villarrasa-Sapina I, Massó XG, Anó PA, Lucerga CG, Gonzalez LM, Lurbe E. Differences in intermittent postural control between normal weight and obese children. Gait Posture. 2016; 49:1-6. DOI: http://dx.doi.org/10.1016/j.gaitpost.2016.06.012

12. World Health Organization (WHO). WHO AnthroPlus software license agreement: on the use of the WHO AnthroPlus for personal computers. Software for assessing growth of the world's children and adolescents. Geneva: WHO, 2009.

13. Dutra GF, Kaufmann CC, Pretto ADB, Albernaz EP. Television viewing habits and their influence on physical activity and childhood overweight. J Pediatr (RIO J). 2015;91(4): 346-51. DOI: http://dx.doi.org/10.1016/j.jped.2014.11.002

14. Farias Junior JC, Lopes AS, Florindo AA, Hallal PC. Validade e reprodutibilidade dos instrumentos de medida da atividade física do tipo self-report em adolescentes: uma revisão sistemática. Cad Saúde Pública. 2010;26(9):1669-91. DOI: http://dx.doi.org/10.1590/S0102-311X2010000900002

15. Crocker PRE, Bailey DA, Faulkner RA, Kowalski KC, McGrath R. Measuring general levels of physical activity: preliminary evidence for the Physical Activity Questionnaire for Older Children. Med Sci Sports Exerc. 1997;29(10):1344-9. DOI: http://dx.doi.org/10.1097/00005768-199710000-00011

16. Mancini M, Horak FB. The relevance of clinical balance assessment tools to differentiate balance deficits. Eur J Phys Rehabil Med. 2010;46(2):239-48.

17. Duarte M, Freitas SMSF. Revisão sobre posturografia baseada em plataforma de força para avaliação do equilíbrio. Rev Bras Fisioter. 2010;14(3):183-92. DOI: http://dx.doi.org/10.1590/S1413-35552010000300003

18. Candotti CT, Nunes SEB, Noll M, Freitas K, Macedo CH. Effects of a postural program for children and adolescents after eight months of practice. Rev Paul Pediatr. 2011;29(4):577-83. DOI: http://dx.doi.org/10.1590/S0103-05822011000400017

19. Scoppa F, Capra R, Gallamini M, Shiffer R. Clinical stabilometry standardization: Basic definitions - Acquisition interval - Sampling frequency. Gait Posture. 2012;37(2):290-2. DOI: https://doi.org/10.1016/j.gaitpost.2012.07.009 
20. Seron BB, Silva RAC, Greguol M. Efeitos de dois programas de exercício na composição corporal de adolescentes com síndrome de Down. Rev Paul Pediatr. 2014;32(1):92-8.

DOI: http://dx.doi.org/10.1590/S0103-05822014000100015

21. Hendrix CG, Prins MR, Dekkers H. Developmental coordination disorder and overweight and obesity in children: a systematic review. Obes Rev. 2014;15(5):408-23. DOI: http://dx.doi.org/10.1111/obr.12137

22. Rimmer JH, Yamaki K, Davis BM, Wang E, Vogel LC. Obesity and overweight prevalence among adolescents with disabilities. Prev Chronic Dis. 2011;8(2):A41.

23. Niehues JR, Gonzales AI, Lemos RR, Bezerra PP, Haas P. Prevalence of Overweight and Obesity in Children and Adolescents from the Age Range of 2 to 19 Years Old in Brazil. Int J Pediatr. 2014;2014:583207. DOI: http://dx.doi.org/10.1155/2014/583207

24. Lobstein R, Jackson-Leach R. Planning for the worst: estimates of obesity and comorbidities in schoolage children in 2025. Pediatr Obes. 2016;11(5):321-5. DOI: http://dx.doi.org/10.1111/ijpo.12185

25. Bertapelli F, Pitetti K, Agiovlasitis S, Guerra-Junior G. Overweight and obesity in children and adolescents with Down syndrome-prevalence, determinants, consequences and interventions: a literature review. Res Dev Disabil. 2016; 57:181-92. DOI: http://dx.doi.org/10.1016/j.ridd.2016.06.018

26. Maiano C, Normand CL, Aimé A, Bégarie J. Lifestyle interventions targeting changes in body weight and composition among youth with an intellectual disability: a systematic review. Res Dev Disabil. 2014; 35(8):1914-26. DOI: http://dx.doi.org/10.1016/j.ridd.2014.04.014

27. Pitetti K, Baynard T, Agiovlasitis S. Children and aolescents with Down syndrome, physical fitness and physical activity. J Sport Health Sci. 2013;2(1):47-57. DOI: https://doi.org/10.1016/j.jshs.2012.10.004

28. Phillips AC, Holland AJ. Assessment of objectively measured physical activity levels in individuals with intellectual disabilities with and without Down's syndrome. Plos One. 2011; 6(12):e28618. DOI: https://doi.org/10.1371/journal.pone.0028618

29. Matute-Llorente A, González-Agüero A, Gómez-Cabello A, Vicente-Rodríguez G, Casajús JA. Physical activity and cardiorespiratory fitness in adolescents with Down syndrome. Nutr Hosp. 2013; 28(4):1151-5. DOI: https://doi.org/10.3305/nh.2013.28.4.6509

30. Izquierdo-Gomez R, Martínez-Gómez D, Acha A, Veiga OL, Villagra A, Diaz-Cueto M. Objective assessment of sedentary time and physical activity throughout the week in adolescents with Down syndrome. Res Dev Disabil. 2014;35(2):482-9. DOI: https://doi.org/10.1016/j.ridd.2013.11.026

31. Silva CMA, Cunha TT, Pfeifer LI, Tedesco AS, Sant'Anna MMM. Percepção de pais e terapeutas ocupacionais sobre o brincar da criança co paralisia cerebral. Rev Bras Educ Espec. 2016;22(2):221-32. DOI: http://dx.doi.org/10.1590/S1413-65382216000200006

32. Gordia AP, Quadros TMB, Silva LR, Santos GM. Conhecimento de pediatras sobre a atividade física na infância e adolescência. Rev Paul Pediatr. 2015;33(4):400-6. DOI: http://dx.doi.org/10.1016/j.rpped.2015.02.001

33. American College of Sports Medicine. ACSM's guidelines for exercise testing and presciption. 8th ed. 2009.

34. Baccouch R, Rebai H, Sahli S. Kung-fu versus swimming training and the effects on balance abilities in young adolescents. Phys Ther Sport. 2015;16(4): 349-54. DOI: http://dx.doi.org/10.1016/j.ptsp.2015.01.004

35. Lemos LFC, David AC, Mota CB. Development of postural balance in Brazilian children aged 4-10 years compared to young adult. Rev Bras Cineantropom Desempenho Hum. 2016;18(4):419-28. DOI: http://dx.doi.org/10.5007/1980-0037.2016v18n4p419

36. Sousa AMM, Barros JF, Sousa BM. Postural control in children with typical development and children with profound hearing loss. Int J Gen Med. 2012;5: 433-9. DOI: http://dx.doi.org/10.2147/IJGM.S28693

37. Hsu Y, Kuan C, Young Y. Assessing the development of balance function in children using stabilometry. Int J Pediatr Otorhinolaryngol. 2009;73(5):737-40. DOI: http://dx.doi.org/10.1016/j.ijporl.2009.01.016

38. Smith AW, Ulmer FF, Wong DP. Gender Differences in Postural Stability Among Children. J Hum Kinet. 2012;33:25-32. DOI: http://dx.doi.org/10.2478/v10078-012-0041-5

39. Zemel BS, Pipan M, Stallings VA, Hall W, Schadt K, Freedman DS, et al. Growth Charts for Children With Down Syndrome in the United States. Pediatrics. 2015;136 (5):e1204-11. DOI: http://dx.doi.org/10.1542/peds.2015-1652

40. Freire F, Thon RA, Costa LT, Duarte E, Gorla Jl. Crescimento somático de crianças e adolescentes brasileiros com síndrome de Down. J Hum Growth Dev. 2015; 25(1):102-7. DOI: http://dx.doi.org/10.7322/jhgd.96787

41. Zimmer M, Desch L. Sensory integration therapies for children with developmental and behavioral disorders. Pediatrics. 2012;129(6):1186-9. DOI: http://dx.doi.org/10.1542/peds.2012-0876 


\section{Resumo}

Introdução: A Síndrome de Down (SD) é considerada condição genética, resultante da presença de cópia extra do material genético do cromossomo 21 , com prevalência mundial de um a cada $700-1000$ nascidos vivos.

Objetivo: Avaliar o controle postural (CP) de crianças e adolescentes com SD e comparar com a idade, sexo, classificação nutricional e prática de atividade física (PAF).

Método: Estudo transversal, amostra de conveniência, com 21 particpantes, 12 meninos e 9 meninas. As crianças foram subdivididas quanto à idade: $G 1-8$ a 9 anos $(n=8)$; $G 2-10(n=7)$; e $G 3-11$ a 12 anos $(n=6)$; score-Z, em eutróficas $(n=9)$ e acima do peso $(n=12)$; praticantes $(n=7)$ e não praticantes $(n=14)$ de atividade física regular. O CP foi avaliado na plataforma de força (PF), na posição pés juntos, permanência de 30 segundos. As variáveis analisadas foram área centro de pressão (COP) e as velocidades médias de oscilação anteroposterior e médio lateral (VEL-AP e VEL-ML). Para análise de normalidade dos dados, foi utilizado o teste Shapiro-Wilk. Os testes KrusKal-Wallis, pós teste de Dunn's e Mann Whitney foram realizados para análise das associações com o CP. A significância estatística foi de $p<0.05$.

Resultados: As medianas de COP, VEL-AP e VEL-ML foram 3,55 [2,13-6,82], 2,81 [2,32-3,16] e 2,98 $[2,42-3,43]$, respectivamente. Não houve diferença no CP em relação ao sexo, classificação nutricional e PAF. As crianças do G3 apresentaram valores menores de VEL-AP (G1=2,88 [2,82-3,21]; G2= 2,94 $[2,35-3,39] ; \mathrm{G} 3=2,27$ [2-2,3]) e VEL-ML $(\mathrm{G} 1=3,22$ [3,14-3,68]; G2= 2,91 [2,52-3,63]; G3=2,34 [2,12,39]).

Conclusão: O sexo, classificação nutricional e PAF não afetaram o CP, no entanto, a idade modificou as estratégias, visto a diferença na velocidade, mas não interferiu o desempenho em relação a área de COP.

Palavras-chave: síndrome de down, equilíbrio postural, atividade motora, antropometria.

${ }^{\odot}$ The authors (2018), this article is distributed under the terms of the Creative Commons Attribution 4.0 International License (http://creativecommons.org/licenses/by/4.0/), which permits unrestricted use, distribution, and reproduction in any medium, provided you give appropriate credit to the original author(s) and the source, provide a link to the Creative Commons license, and indicate if changes were made. The Creative Commons Public Domain Dedication waiver (http://creativecommons.org/publicdomain/ zero/1.0/) applies to the data made available in this article, unless otherwise stated. 